\title{
Vessel Collision Frequency Estimation in the Singapore Strait
}

\author{
Jinxian Weng ${ }^{1,2}$, Qiang Meng ${ }^{2}$, Xiaobo Qu ${ }^{2}$ \\ 1 (Centre for Maritime Studies, National University of Singapore,) \\ 2(Department of Civil and Environmental Engineering, National University of Singapore)
}

(Email: ceemq@nus.edu.sg)

This paper aims to estimate Vessel Collision Frequency in the Singapore Strait. This frequency is obtained as the product of the number of Vessel Conflicts and the causation probability using the realtime vessel movement data from Lloyd's Marine Intelligence Unit (Lloyd's MIU) database. The results show that the container carriers have the highest Vessel Collision Frequency while Roll-On Roll-Off (RORO) and passenger ships have the lowest frequency. Tankers cause the highest head-on collision frequency. In the Singapore Strait, the most risky overtaking area is between longitudes $103^{\circ} 48^{\prime} \mathrm{E}$ and $104^{\circ} 12^{\prime} \mathrm{E}$. The most risky head-on area is between longitudes $103^{\circ} 50^{\prime} \mathrm{E}$ and $104^{\circ} 00^{\prime} \mathrm{E}$ while the majority of crossing collisions occur between longitudes $103^{\circ} 48^{\prime} \mathrm{E}$ and $104^{\circ} 02^{\prime} \mathrm{E}$. The Vessel Collision Frequency is found to be 1.75 per year in the traffic lanes. Currently, westbound traffic in the Strait is more risky than eastbound (the number of westbound collisions in July was 0.0991 while the number of eastbound collisions was 0.0470). Furthermore, the estimated Vessel Collision Frequency during the day is less than that at night. The results of this paper could be beneficial for the Maritime and Port Authority of Singapore to further enhance the navigational safety strategies implemented in the Singapore Strait.

\section{KEY WORDS}

\section{AIS. 2. Vessel Conflict. 3. Vessel Collision Frequency.}

1. INTRODUCTION. The Singapore Strait is a 105 kilometre long strait between the Strait of Malacca in the west and the South China Sea in the east. It links one of the largest ports to the rest of the world and has a high density of vessel traffic. More than 200 vessels pass through the Strait on a daily basis and this gives an annual throughput of approximately 70,000 vessels, carrying $80 \%$ of the oil transported to Northeast Asia, as well as one third of the world's traded goods including Chinese manufactures, Indonesian coffee etc. Although the Singapore Strait is of great importance to the global economy (Wang and Meng, 2011; Qu and Meng, 2012), it is not deep enough for some of the largest vessels (mostly oil tankers). The Strait also has substantial sections of narrower and shallower shipping lanes. At Philips Channel, it narrows to 2.8 kilometres wide, with 2.1 kilometres in the shipping lanes, creating one of the world's chokepoints. Therefore, the navigational safety of vessels through the Singapore Strait is a matter of great concern to the Maritime and Port Authority (MPA) of Singapore and other relevant stakeholders such as oceanic carriers.

Several strategies for enhancing navigational safety in the Strait have been implemented over the past 30 years. The Traffic Separation Scheme (TSS) was brought into force on 1 May 1981 to enable safer navigation in the Straits of Malacca and Singapore (see Figure 1). Since then, the opposing streams of traffic have been separated by the establishment of traffic lanes. In 1998, the Society of International Gas Tanker and Terminal Operators Ltd (SIGTTO) published the first version of the Passage Planning Guide: Malacca \& Singapore Straits, including background and 
passage notes on the Straits, to provide guidance for ship masters and navigating officers transiting the Straits (SIGTTO, 2008). Different navigational rules, such as sailing speed limits, have been proposed at different locations on the Singapore Strait. The effectiveness of these risk mitigation measures can be assessed using the Quantitative Risk Assessment (QRA) models developed for maritime transportation ( $\mathrm{Li}$ et al., 2011). The most important contributing input into such models is the Vessel Collision Frequency, defined as the product of the number of Vessel Conflicts and the causation probability. This paper focuses on the estimation of Vessel Collision Frequency in the Singapore Straight.

1.1. Literature Review. When looking into Vessel Collision Frequency, 'conflict' and 'probability' are the two key concepts involved. (Macduff, 1974) was the first to define the collision frequency as the number of Vessel Conflicts multiplied by a causation probability. In most previous research, the causation probability for distinct water areas is assumed to be a constant under a particular accident scenario (Kaneko, 2002). However, the number of Vessel Conflicts is dependent on the geometric parameters of the water area, vessel size, traffic volume, vessel Speed Over Ground (SOG) and Course Over Ground (COG). In other words, the accuracy of the Vessel Collision Frequency primarily depends on the accurate estimation of the number of Vessel Conflicts.

Macduff (1974) applied the molecular collision theory to estimate the number of Vessel Conflicts by assuming that the main vessel stream moves with the same speed and along the same course. This assumption is obviously unrealistic and may result in underestimation. Fujii (1971) proposed a model based on geometry and the laws of motion to estimate the average number of conflicts when vessels pass through a given area. However, the results are overestimated to some extent because the evasive actions are assumed to take up between 9.5 and 16.3 times of the vessel length, which is very conservative in practice. In reality, the minimum vessel distance, which is defined as the safe distance between two vessels at the moment of closest approach based on their measurement points (i.e., the 'points' of the vessel's radar echoes on the radar screen) is about three times the vessel length in the Singapore Strait. Following Fujii's pioneering work, the ship domain concept was proposed to estimate the number of Vessel Conflicts (Pietrzykowski, 2008; Pietrzykowski and Uriasz, 2009; Szlapczynski, 2006; Wang, 2010). For example, Fowler and Sorgard (2000) developed a ship domain based model by assuming there is a critical situation when two vessels cross within 0.5 nautical miles of each other. (Pedersen, 2002) also applied the ship domain theory to conduct a risk analysis for a large suspension bridge. However, again, the minimum distance between two vessels was assumed to be a constant and only head-on conflicts were taken into account.

The computer simulation based approach can quantitatively examine various navigational safety issues. Dand (2001) introduced the Permanent International Association of Navigation Congresses (PIANC) simulation approach to the water channel design. (Zhang and Huang, 2006) developed ship models to acquire pilot experience using the computer simulation approach. However, the simulation method is very time-consuming. It may also give rise to biased or inaccurate results because of a lack of practical criteria and incorrect interpretations of rules and seamanship. It is thus not rational to estimate the number of Vessel Conflicts using a simulation approach.

A mathematical model was recently proposed by (COWI, 2008) to estimate the number of overtaking or head-on Vessel Conflicts. In this model, the number of Vessel Conflicts depends on the route segment length, traffic intensity in each of the two sailing directions, the widths and speeds of the vessels, and the deviation of the vessels from the route axis. This model usually 
overestimates the overtaking and head-on collision frequencies because the dependency of consecutive vessels is not taken into account.

In addition to the above-mentioned methods and models, several other models and methods have also been proposed by researchers. A simple random walk model was built by Tan and Otay (1999) to estimate the number of Vessel Conflicts. To assess the navigational safety of the Singapore Strait, (Qu et al., 2011) put forward three ship collision risk indices: speed dispersion, the degree of acceleration and deceleration, and the number of ship domain overlaps.

1.2. Objectives \& Contributions. This study aims to estimate Vessel Collision Frequency in the Singapore Strait. The Vessel Collision Frequency is calculated as the product of the number of Vessel Conflicts and the causation probabilities. The number of Vessel Conflicts is computed by using real-time vessel information, provided by Lloyd's Marine Intelligence Unit's (Lloyd's MIU) Automatic Identification System (AIS). Based on the estimated number of Vessel Conflicts, the most risky area in the Singapore Strait can be identified. The effects of vessel course and time period on Vessel Collision Frequency are also investigated.

The contributions of this study are twofold. First, it initiates research into estimating Vessel Collision Frequency in the Singapore Strait. Second, the results from this study can be used by the MPA of Singapore to choose appropriate navigational safety strategies.

The remainder of this paper is organized as follows: Section 2 introduces the Lloyd's MIU AIS data and the data processing methods; in Section 3, the Vessel Collision Frequency estimation model is formulated, followed by the results and discussions in Section 4; conclusions of this study are presented in the last section.

\section{DATA.}

2.1. Data Collection. The International Maritime Organization (IMO) International Convention for the Safety of Life at Sea (SOLAS) has required since 2002 that all larger seagoing vessels (>300GT) and all passenger vessels should be equipped with an AIS (Mou et al., 2010). Through dedicated Very High Frequency (VHF) radio, AIS information can be transmitted between vessels, from vessels to shore and vice versa. In simple terms, AIS is a technology which makes vessels 'visible' to each other. It can record information on vessel behaviour, including the effects of human behaviour and vessel manoeuvrability.

One month's (July 2009) AIS data from the Lloyd's MIU AIS database are used in this study. A total of 166,182 AIS records were collected to evaluate the Vessel Collision Frequency in the Singapore Strait between longitudes $103^{\circ} 21^{\prime} \mathrm{E}$ and $104^{\circ} 35^{\prime} \mathrm{E}$, as shown in Figure 1 . The dashed lines in Figure 1 indicate the TSS for the Singapore Strait. Each AIS record comprises the following information for each vessel at each reporting time (every 3 to 10 seconds): MMSI (Maritime Mobile Service Identity) number, latitude position, longitude position, SOG and COG.

\section{(Insert: Figure 1. Insert: Figure 1 caption.)}

2.2. Data Processing. Although the majority of the AIS records collected are accurate, a few records have inaccurate position and speed information. For example, it is found that $0.18 \%$ of the longitude position data are outside the range from $103^{\circ} 21^{\prime} \mathrm{E}$ to $104^{\circ} 35^{\prime} \mathrm{E}$, and $0.25 \%$ of the SOG data exceed an unbelievable speed of 50 knots. To deal with these inaccurate SOG and position data, the data cleansing method proposed by (Qu et al., 2011) is employed in this study. Additionally, more than 35\% of the AIS records do not include the vessel length. It would be inappropriate to delete this incomplete data as it would interfere with the integrity of the real- 
time data. Since the vessel length is a key parameter in the estimation of Vessel Collision Frequency, we propose the following procedure for determining the missing vessel length by dividing the AIS records that lack vessel lengths into two categories:

- Category 1: (Missing vessel length for a vessel with an IMO number). Vessel length is highly correlated with the following factors: Net Register Tonnage (NRT), Gross Tonnage (GT) and Dead Weight Tonnage (DWT). However, the values of NRT and DWT are sometimes unavailable and given as null. Considering the availability of the above factors, we first classify the data in this category into the following four groups:

i) NRT $=$ null and DWT $\neq$ null.

ii) NRT=null and DWT=null.

iii) NRT $\neq$ null and DWT $=$ null.

iv) Otherwise.

For each group, we then use the multiple linear regression method to estimate the coefficients associated with the four factors. Using this method, the vessel length $l$ could be formulated as the following piecewise function:

$$
I=\left\{\begin{array}{l}
120+0.00141 G T, \text { if } N R T=\text { null and } D W T \neq \text { null, } R^{2}=89.5 \% \\
25.2+0.0202 G T, \text { if } N R T=\text { null and } D W T=\text { null, } R^{2}=81.0 \% \\
50.4, \quad \text { if } N R T \neq \text { null and } D W T=\text { null, } R^{2}=79.8 \% \\
136+0.00129 G T+0.000104 D W T, \quad \text { othewise, } R^{2}=85.0 \%
\end{array}\right.
$$

The vessel length function in Equation (1) can provide an accurate estimate because of the high prediction performance ( i.e., high $\mathrm{R}^{2}$ ).

- Category 2: (Missing vessel length for a vessel without an IMO number). For vessels in this category, the missing vessel lengths will be assigned by the average value $(\approx 197 \mathrm{~m})$ of all vessel lengths available in the database.

3. VESSEL COLLISION FREQUENCY MODEL. Motivated by the work of (Fujii et al., 1974); MacDuff, 1974) and (Mou et al., 2010), the Vessel Collision Frequency in this study is estimated by:

$$
f=N p_{c}
$$

where:

$f$ is the collision frequency of the vessels.

$N$ is the number of Vessel Conflicts

$p_{c}$ is the causation probability, which is the probability of failing to avoid a collision for a given Vessel Conflict.

To calculate the numbers of Vessel Conflicts, we take a time interval of three minutes ( $\Delta T=3$ minutes) over which we analyse the collected AIS data. A Vessel Conflict is defined as a critical situation where a vessel is expected to enter another vessel's ship domain in the next time interval (Montewka et al., 2010). Here, the ship domain is expressed as the area around the vessel that the navigator wants to keep clear of other vessels or objects (Goodwin, 1975). Figure 2 shows an example of a Vessel Conflict, where Vessel B is going to intrude into the domain of 
Vessel A in the following time interval $\Delta T$. Note that the radius $(R)$ of Vessel A's domain is not fixed but changes with vessel length. It can be shown that the majority of domain radiuses are approximately three times the vessels' length (Mou et al., 2010). Hence, the domain radius of a particular vessel $i$ can be estimated simply by:

$$
R_{i}=3 l_{i}
$$

where $R_{i}$ is the domain radius for vessel $i$ and $l_{i}$ is the length of vessel $i$.

(Insert: Figure 2. Insert: Figure 2 caption.)

Let $\left(x_{i}^{t}, y_{i}^{t}\right)$ denote the position of a particular vessel $i$ at time $t ; \vec{v}_{i}^{t}$ and $\alpha_{i}^{t}$ denote the speed and course of vessel $i$ at time $t$, respectively. Similarly, $\left(x_{j}^{t}, y_{j}^{t}\right)$ denotes the position of another vessel $j$ at time $t ; \vec{v}_{j}^{t}$ and $\alpha_{j}^{t}$ represent the speed and course of vessel $j$ at time $t$, respectively. The relative speed of vessel $i$ over vessel $j$ at time $t$, denoted by $\vec{V}_{i j}^{t}$, can be calculated by

$$
\left|\vec{V}_{i j}^{t}\right|=\sqrt{\left(\left|\vec{v}_{i}^{t}\right| \cos \alpha_{i}^{t}-\left|\vec{v}_{j}^{t}\right| \cos \alpha_{j}^{t}\right)^{2}+\left(\left|\vec{v}_{i}^{t}\right| \sin \alpha_{i}^{t}-\left|\vec{v}_{j}^{t}\right| \sin \alpha_{j}^{t}\right)^{2}}
$$

The distance between vessel $i$ and vessel $j$ at time $t$, denoted by $D_{i j}^{t}$, can be computed by

$$
D_{i j}^{t}=\sqrt{\left(x_{i}^{t}-x_{j}^{t}\right)^{2}+\left(y_{i}^{t}-y_{j}^{t}\right)^{2}}
$$

Let $\theta_{i j}^{t}$ be the angle between the relative speed $\vec{V}_{i j}^{t}$ and the line connecting two vessels, as shown in Figure 3. The angle $\theta_{i j}^{t}$ can be calculated by:

$$
\theta_{i j}^{t}=\arccos \left(1-\frac{\left(\frac{\left|\vec{V}_{i}^{t}\right| \sin \alpha_{i}^{t}-\left|\vec{V}_{j}^{t}\right| \sin \alpha_{j}^{t}}{\left|\vec{V}_{i j}^{t}\right|}-\frac{x_{j}^{t}-x_{i}^{t}}{D_{i j}^{t}}\right)^{2}+\left(\frac{\left|\vec{V}_{i}^{t}\right| \cos \alpha_{i}^{t}-\left|\vec{V}_{j}^{t}\right| \cos \alpha_{j}^{t}}{\left|\vec{V}_{i j}^{t}\right|}-\frac{y_{j}^{t}-y_{i}^{t}}{D_{i j}^{t}}\right)^{2}}{2}\right)
$$

(Insert: Figure 3. Insert: Figure 3 caption.)

If vessel $i$ is expected not to enter vessel $j$ 's domain during the next time interval, the maximum sailing distance $\left({ }^{L_{i j}}\right)$ at time $t$ can be calculated by:

$$
L_{i j}^{t}=D_{i j}^{t} \cos \theta_{i j}^{t}-\sqrt{R^{2}-\left(D_{i j}^{t} \sin \theta_{i j}^{t}\right)^{2}}
$$

Hence, vessel $i$ has a conflict with vessel $j$ at time $t$ if and only if the following condition holds: 


$$
0<L_{i j}^{t} \leq\left|\vec{V}_{i j}^{t}\right| \cdot \Delta T
$$

There are three types of Vessel Conflicts, defined as follows:

i) Overtaking Conflict. An overtaking conflict means a conflict in which two vessels are proceeding on the same route, lying on almost parallel courses. The course difference of an overtaking should not exceed $10^{\circ}$ (Montewka et al., 2010).

a) Head-On Conflict. A head-on conflict is referred to as a conflict in which vessels are lying on almost reciprocal courses, and the course differences falls in the range from $170^{\circ}$ to $190^{\circ}$.

ii) Crossing Conflict. A crossing conflict is a conflict in which the difference between two vessels' courses falls in the range $10^{\circ}-170^{\circ}$ or $190^{\circ}-350^{\circ}$.

It should be pointed out that the course classifications used in this study are different from those in the International Regulations for the Prevention of Collisions at Sea (COLREGS). This study adopts the course classification scheme from (Montewka et al., 2010) because this classification scheme could slightly overestimate collision risk, compared with COLREGS. In view of the high safety requirement in the Singapore Strait, it is reasonable to use this conservative course classification scheme. As a vessel may encounter all three of the above Vessel Conflict types, the Vessel Collision Frequency could be estimated as:

$$
f=N_{\text {overtaking }} p_{c}^{\text {overtaking }}+N_{\text {head-on }} p_{c}^{\text {head -on }}+N_{\text {crossing }} p_{c}^{\text {crossing }}
$$

where:

$N_{\text {overtaking }}$ is the number of overtaking conflicts.

$p_{c}^{\text {overtaking }}$ is the causation probability for the overtaking conflicts.

$N_{\text {head-on }}$ is the number of head-on conflicts.

$p_{c}^{\text {head-on }}$ is the causation probability for the head-on conflicts.

$N_{\text {crossing }}$ is the number of crossing conflicts.

$p_{c}^{\text {crossing }}$ is the causation probability for the crossing conflicts.

\section{RESULTS AND DISCUSSION.}

4.1. Vessel Traffic Characteristics. This section mainly presents the characteristics of vessels involved in conflicts. The vessels sailing in the Singapore Strait can be divided into six groups: general cargo vessels, bulk carriers, tankers, Liquefied Natural Gas/Liquefied Petroleum Gas (LNG/LGP), Roll-On Roll-Off (RORO)/Passenger ships and container carriers. Table 1 gives each category's percentage share of the traffic in the Singapore Strait, based on our one month of AIS data. According to Table 1, it can be clearly seen that container carriers account for the biggest proportion (36.36\%), followed by bulk carriers (20.50\%) and then tankers (18.30\%). The percentage of RORO/Passenger ships (4.77\%) in the Strait is quite small.

(Insert: Table 1. Insert: Table 1 Caption.

To investigate the relative speed of two vessels involved in a conflict, the @Risk software (@Risk, 2002) is used to fit relative speed distributions. This software makes use of chi-squared fit statistic to measure how well a distribution fits the collected data. Those which fit best (with 
the lowest chi-squared statistics) are selected. Figure 4 includes three graphs which describe the best-fitted distributions of relative speed for vessels involved in the three different types of Vessel Conflict. Figure 4(a) shows that the Weibull distribution best describes the relative speed of two vessels involved in an overtaking conflict. The majority of relative speeds (79.9\%) range from 1 to 5 knots, and the average relative speed is around 3 knots. Figure 4(b) indicates that the average relative speed in head-on conflicts is 12 knots. The three graphs in Figure 4 demonstrate that the relative speeds of vessels involved in head-on conflicts are generally larger than those of vessels involved in overtaking and crossing conflicts. Since higher relative speeds could cause more serious consequences, a head-on collision is more likely to be associated with a high level of severity.

(Insert: Figure 4. Insert: Figure 4 caption.)

4.2. Vessel Collision Frequency. Figure 5 shows the compositions of vessel traffic involved in the different types of Vessel Conflict. According to Figure 5(a), container carriers, bulk carriers and tankers are the three main types of vessels involved in overtaking conflicts, representing $73.64 \%$ of all vessels involved. Furthermore, the container carrier is the most risky vessel type in terms of overtaking conflicts because it makes up the largest percentage. Figure 5(b) shows that the majority of head-on conflicts (79.78\%) are again caused by these three vessel types. However, tankers rather than container carriers have the highest head-on collision frequency. The difference may be due to the rules for vessels navigating in the Singapore Strait. According to one of the rules, eastbound deep draught vessels (i.e., tankers) should use the deep water routes. Since the deep water routes are adjacent to the westbound traffic routes, tankers would certainly have more chance of colliding head-on with westbound vessels. In addition, another rule implies that eastbound tankers navigating in the deep water routes should avoid overtaking, which decreases the likelihood of tankers being involved in overtaking collisions. Figure 5(c) shows that the above three vessel types account for the majority of crossing conflicts as well, suggesting that the three vessel types are again the most risky in terms of crossing collision frequency. Due to the high percentage of Vessel Conflicts that involve tankers, and the severe consequences of such conflicts, focus may be placed on the tracking and management of tanker traffic.

\section{(Insert: Figure 5. Insert: Figure 5 caption.)}

The spatial distributions for different types of Vessel Conflicts in the Singapore Strait are presented in Figure 6. Figure 6(a) clearly shows that the most risky overtaking area is between longitudes $103^{\circ} 48^{\prime} \mathrm{E}$ and $104^{\circ} 12^{\prime} \mathrm{E}$ because of a greater number of overtaking conflicts. The high risk of overtaking collision may be caused by speeding vessels within this area (Qu et al., 2011). According to the Passage Planning Guide: Malacca \& Singapore Straits (SIGTTO, 2008), the eastbound vessels reduce their speed to 12 knots in this area while the westbound vessels increase their speed from 12 knots if conditions are suitable. Therefore, there is a high frequency of vessel acceleration and deceleration manoeuvers within this area, which produces a larger number of overtaking conflicts. In addition, the traffic width in this area (specifically between longitudes $103^{\circ} 50^{\prime} \mathrm{E}$ and $104^{\circ} 00^{\prime} \mathrm{E}$ ) is narrower than in other areas (see Figure 1 ). Hence, the density of vessels within this area is the largest in the entire Singapore Strait. This suggests that the vessels navigating in this area have the biggest probability of being involved in head-on 
conflicts, as shown in Figure 6(b). Figure 6(c) depicts the spatial distribution of vessel crossing conflicts. It can be seen that there are three areas associated with a high frequency of crossing conflicts. Two of them have a small peak centred at about $103^{\circ} 40^{\prime} \mathrm{E}$ and $104^{\circ} 16^{\prime} \mathrm{E}$, respectively. It should be pointed out that the first small peak is in the crossing area between longitudes $103^{\circ} 30^{\prime} \mathrm{E}$ and $103^{\circ} 40^{\prime} \mathrm{E}$ while the other small peak is in the crossing area between longitudes $104^{\circ} 04^{\prime} \mathrm{E}$ and $104^{\circ} 18^{\prime} \mathrm{E}$. One possible reason for a little higher frequency of crossing conflicts in the two areas might be that the slow-moving very large crude carriers (i.e., LNG/LGP) bound to or from the Shell SBM terminal sometimes cross the traffic lanes in these areas. The increase in the number of crossing manoeuvers could increase the number of crossing conflicts. From the figure, it can also be seen that the majority of crossing conflicts are distributed in the area between longitudes $103^{\circ} 50^{\prime} \mathrm{E}$ and $104^{\circ} 12^{\prime} \mathrm{E}$. This may be due to the fact that vessels from the Singapore Port cross to the eastbound lane or merge into the westbound lane in this area.

\section{(Insert: Figure 6. Insert: Figure 6 caption.)}

In the next step, the probability of a collision is computed on the basis of the number of conflicts obtained and the causation probability values adopted. We use three causation probability values which are commonly accepted in the existing studies (Pedersen, 2002; Otto et

al., 2002; Kujala et al., 2009): $p_{c}^{\text {overtaking }}=1.30 \times 10^{-4}$ for the crossing conflict, $p_{c}^{\text {head }- \text { on }}=4.90 \times 10^{-5}$ for the overtaking conflict, and $p_{c}^{\text {crossing }}=4.90 \times 10^{-5}$ for the head-on conflict. Table 2 shows the estimated Vessel Collision Frequency in the Singapore Strait. The estimated collision frequency (1.75 per year) is quite close to the average actual frequency of 1.80 per year, calculated from historical accident records for the Singapore Strait between the years of 1997 and 2002.

(Insert: Table 2. Insert: Table 2 Caption.

4.3. Effects of Course and Time of Day on Vessel Collision Frequency. Table 3 shows the effects of course on the number of collisions in July 2009. From Table 3, it is clear that fewer overtaking, head-on and crossing collisions occur in the eastbound lanes than in the westbound lanes. Overall, westbound traffic has a collision frequency approximately twice that of eastbound traffic. One possible reason for this is that the lane width for the westbound traffic is narrower than that for the eastbound traffic although traffic volumes are similar in each course.

(Insert: Table 3. Insert: Table 3 Caption.

Table 4 demonstrates that the Vessel Collision Frequency during the day is lower than the frequency at night. A one-way ANalysis Of VAriance (ANOVA) analysis is also carried out to test whether the night Vessel Collision Frequency is statistically higher than the day Vessel Collision Frequency. Table 5 gives the ANOVA test results, showing that the overtaking collision frequency during the day is statistically lower than the night frequency, at a significance level of 0.05 . Similarly, both the head-on and crossing collision frequencies during the day are statistically lower than those at night. The higher collision frequency among night vessel traffic 
may be explained by the large concentration of small fishing crafts in the Singapore Strait, which may not be fully detectable at night by radar.

(Insert: Table 4. Insert: Table 4 Caption.

(Insert: Table 5. Insert: Table 5 Caption.

5. CONCLUSIONS. This study estimated Vessel Collision Frequency in the Singapore Strait using data from Lloyd's MIU AIS vessel movement database. According to the results, it can be seen that container carriers have the highest Vessel Collision Frequency while RORO/Passenger ships have the lowest collision frequency. Tankers have the highest head-on collision frequency. Due to the high percentage of Vessel Conflicts involving tankers and their severe consequences, focus should perhaps be placed on the tracking and management of tanker traffic in the Singapore Strait.

The results further show that the most risky overtaking area is between longitudes $103^{\circ} 48^{\prime} \mathrm{E}$ and $104^{\circ} 12^{\prime} \mathrm{E}$. The most risky head-on area is between longitudes $103^{\circ} 50^{\prime} \mathrm{E}$ and $104^{\circ} 00^{\prime} \mathrm{E}$. The majority of crossing collisions are distributed in the area between longitudes $103^{\circ} 48^{\prime} \mathrm{E}$ and $104^{\circ} 02^{\prime} \mathrm{E}$. The Vessel Collision Frequency in the Singapore Strait is found to be 1.75 per year. It is also found that westbound traffic has about twice the collision frequency of the eastbound traffic. Moreover, the Vessel Collision Frequency during the day is lower than that at night. It should be pointed out that this study is just a first step towards quantitatively assessing the casualty risk in the Singapore Strait. The estimated Vessel Collision Frequency should next be used in QRA modelling.

\section{ACKNOWLEDGMENTS}

This study is one part of the research project 'Development of QRA model and software for shipping operations in the Straits of Malacca and Singapore' funded by Maritime Innovation and Technology Fund of Singapore (WBS No. R-264-000-281-490 and R-702-000-004-490).

\section{REFERENCES}

COWI, (2008). Risk Analysis of Sea Traffic in the Area Around Bornholm. Kongens Lyngby, Denmark: COWI A/S, Report \# P-65775-002.

Fowler, T.G. and Sorgrad, E. (2000). Modelling ship transportation risk. Risk Analysis, 20, 225-244.

Fujii, Y. and Tanaka, K. (1971). Traffic Capacity. Journal of Navigation, 24, 543-552.

Fujii, Y., Yamanouchi, H. and Mizuki, N. (1974). Some Factors Affecting the Frequency of Accidents in Marine Traffic. II-The Probability of Stranding. III- The Effect Of Darkness on The Probability of Collision ond Stranding. Journal of Navigation, 27, 239-247.

Dand, I.W. (2001). Approach Channel Design: The PIANC Approach. Proceedings of the International Workshop on Channel Design and Vessel Maneuverability, Norfolk, VA.

Goodwin, E.M. (1975). A statistical study of ship domains. Journal of Navigation, 28, 328-344.

Kaneko, F. (2002). Methods for probabilistic safety assessments of ships. Journal of Marine Science and Technology, 7, 1-16.

Kujala, P., Hanninen, M., Arola, T. and Ylitalo, J. (2009). Analysis of the Marine Traffic Safety in the Gulf of Finland. Reliablity Engineering and System Safety, 94, 1349-1357.

Li, S., Meng, Q. and Qu, X. (2011). An overview of maritime waterway quantitative risk assessment models. Risk Analysis (Accepted). 
MPA. Maritime and Port Authority of Singapore. http://www.mpa.gov.sg/sites/port_and_shipping/port/vessel_traffic_information_system(vtis)/straitrep/ operational_areas.page, accessed on 30 August 2011.

Macduff, T. (1974). Probability of Vessel Collisions. Ocean Industry, 9, 144-148.

Montewka, J., Hinz, T., Kujala, P. and Matusiak, J. (2010). Probability Modelling of Vessel Collisions. Reliability Engineering and System Safety, 95, 573-589.

Mou, J.M., Tak, C. and Ligteringen, H. (2010). Study on Collision Avoidance in Busy Waterways by Using AIS Data. Ocean Engineering, 37, 483-490.

Otto, S., Pedersen, P.T., Samuelides, M. and Sames, P.C. (2002). Elements of Risk Analysis for Collision and Grounding of a RoRO Passenger ferry. Marine Structures, 15, 461-474.

Pedersen, P. (2002). Collision Risk for Fixed Offshore Structures Close to High-Density Shipping Lane. Proceedings of the Institution of Mechanical Engineers Part M: Journal of Engineering for the Maritime Environment, 216, 29-44.

Pietrzykowski, Z. (2008). Ship's Fuzzy Domain - A Criterion for Navigational Safety in Narrow Fairways. Journal of Navigation, 61, 499-514.

Pietrzykowski, Z. and Uriasz, J. (2009). The Ship Domain - A Criterion of Navigational Safety Assessment in an Open Sea Area. Journal of Navigation, 62, 93-108.

Qu, X., Meng, Q., Li, S. (2011). Ship Collision Risk Assessment for the Singapore Strait. Accident Analysis and Prevention, 43, 2030-2036.

Qu, X., and Meng Q. (2012). The economic importance of the Straits of Malacca and Singapore: an extreme-scenario analysis. Transportation Research Part E: Logistics and Transportation Review. 48, 258-265.

@RISK. (2002). Risk Analysis and Simulation Add-in for Microsoft® Excel (version 4.5).

SIGTTO. (2008). Passage Planning Guide: Malacca \& Singapore Straits (2nd Edition 2008). Witherby Seamanship International Ltd.

Szlapczynski, R. (2006). A Unified Measure of Collision Risk Derived from the Concept of a Ship Domain. Journal of Navigation, 59, 477-490.

Tan, B. and Otay, E.N. (1999). Modelling and Analysis of Vessel Casualties Resulting from Tanker Traffic Through Narrow Waterways. Naval Research Logistics, 46, 871-892.

Wang, N. (2010). An Intelligent Spatial Collision Risk Based on the Quaternion Ship Domain. Journal of Navigation, 63, 733-749.

Wang, X. and Meng, Q. (2011). The Impact of Landbridge on the Market Shares of Asian Port. Transportation Research Part E, 47, 190-203.

Zhang, H., and Huang, S. (2006). Dynamic Control of Intention Priorities of Human-like Agents. Proceedings of the $17^{\text {th }}$ European Conference on Artificial Intelligence, ECAT 2006, Italy. 